\title{
Effects of Critical Thinking and Communication Skills on the Problem-Solving Ability of Dental Hygiene Students
}

\author{
Ji-Hyoung Han ${ }^{1}$, Eunsuk $\mathrm{Ahn}^{2}$, and Ji-Min Hwang ${ }^{3, \dagger}$ \\ ${ }^{1}$ Department of Dental Hygiene, Suwon Science College, Hwaseong 18516, \\ ${ }^{2}$ Department of Dental Hygiene, Kyungbok University, Pocheon 11138, \\ ${ }^{3}$ Department of Dental Hygiene, Baekseok Culture University, Cheonan 31065, Korea
}

\begin{abstract}
Background: This study aimed to investigate the effects of critical thinking and good communication skills on the problem-solving abilities of dental hygiene students.

Methods: A total of 508 dental hygiene students were convenience-sampled from 3 universities.

Results: The results revealed that critical thinking had the highest intellectual fairness score of 3.60, and systematicity was the lowest at 3.19. The values for communication skills were high in reaction, social adequacy, and concentration, with an average of 3.65. Problem-solving abilities were in the following order: clarification of the problem, seeking solutions, and decision making. According to general characteristics, more extroverted personalities possessed higher levels of critical thinking, communication skills, and problem-solving abilities $(p<0.01)$. Critical thinking scores were high $(p=0.016)$ in students who responded that peer relationship was difficult; however, their communication skills were the lowest $(p<0.001)$. Additionally, problem-solving abilities were highest among students who reported a difficult peer relationship $(p=0.001)$. The higher the satisfaction with dental hygiene academics, the higher the critical thinking, communication skill, and problem-solving ability $(p<0.001)$. Critical thinking showed a high positive correlation with variables in the following order: clarification of the problem, performing the solutions, seeking solutions, decision making, and evaluation and reflection. The communication skills were also related to these variables listed above $(p<0.01)$. With critical thinking, confidence, watchfulness, intellectual passion/curiosity, sound skepticism, objectivity, and systematicity all influenced the problem-solving ability. Conclusion: Communication skills were influenced by noise control, putting on the other's shoe, social tensions, and efficiency, which affected the problem-solving ability. Dental clinics require dental hygienists to have critical thinking to make analytical judgments and effective communication skills to solve human relation problems with patients and care-givers. Therefore, these skills should be developed in dental hygiene students to improve their problem-solving abilities.
\end{abstract}

Key Words: Communication, Critical thinking, Dental hygiene, Problem-solving

\section{Introduction}

The World Economic Forum has adopted 16 technologies from the 21st century, which are necessary for students living in this era. The core competencies among basic questions, core competencies, and personality qualities are the necessary factors for students to overcome complex challenges through the application of critical thinking, problem-solving, creativity, and communication ${ }^{1)}$.
In addition, the New Dental Hygienist Competency Statement, published by the American Council on Dental Education, reports that its required competencies needed for evidence-based dental hygiene practice involves the application of critical thinking and problem-solving abilities $^{2}$. Hence, according to these changes and demands of the times, critical thinking, communication skills, and problem-solving abilities for dental hygienists and students are essential for the theoretical application of 
knowledge and technology to clinical practice.

Critical thinking is the ability to determine the logical structure and meaning of linguistic expressions and behaviors in order to determine what views to accept, what to do, and how to make the best judgments based on the concepts, evidences, criteria, methods, and contexts ${ }^{3)}$. Critical thinking is essential for analyzing the information of subjects and the application of the appropriate procedures to solve problems during the dental hygiene process. It is also important to improve the decisionmaking capabilities, and to improve the quality of performance and patient care ${ }^{4)}$. Wilkins ${ }^{5)}$ recommends the application of critical thinking skills in data processing, including classification, interpretation, and validation during the diagnosis phase of dental hygiene. Kim et al. ${ }^{6}$ proposed the necessity of reviewing the dental hygiene education as a methodological approach to critical thinking. In addition, a newer curriculum is needed to help students organize their knowledge and express their opinions in order to develop critical thinking.

Communication is a dynamic and simultaneous interchange between participants. It is also a complex action that receives and accepts its message in verbal and non-verbal ways ${ }^{7)}$. Communication skills are required to communicate effectively, and it is the ability to accurately convey one's thoughts and feelings to others ${ }^{8)}$. If there is a lack of communication skills, one's intention may be misinterpreted, causing conflicts with the other party or lowering their problem-solving abiliy" ${ }^{9)}$ Effective communication skills at medical service sites, which are diversified and systematically established day by day, are emphasized as the basic qualities of dental hygienists ${ }^{10)}$. In addition, effective communication skills can be an important means of solving problems through patient interaction; thus improving the quality of oral health services and patient satisfaction.

Problem-solving ability is the intellectual and creative ability to recognize and resolve differences between the current status the projected goals ${ }^{11)}$. The ability to solve problems is the ability to solve them by using communication skills, not only in clinical practice but also in potential problems. Problem-solving skills also play a critical role in the way the individual interacts with the environment and process information about problem situations $^{12,13)}$. The National Institute of Education's report on the improvement of university education in the United States also emphasizes the importance of problem- solving abilities, such as the ability to think critically, communicate effectively, and solve problems ${ }^{14)}$. Therefore, the development and research of the best educational system to improve critical thinking, communication skill, and problem-solving ability are steadily being carried out.

The purpose of this study was to investigate the effects of critical thinking and communication skills on the problem-solving ability of dental hygiene students. Additionally, this study will be used as basic data to search for ways to develop the curriculum and improve the problem-solving ability in the dental hygiene field.

\section{Materials and Methods}

\section{Subjects and methods}

Using a convenience sampling method, this study enrolled dental hygiene students in two universities in Gyeonggi-do and one university in Chungnam. The survey period was from August 27 to September 15, 2018. For ethical reasons, the study was conducted with the consent of the subjects. The sample size was based on the $\mathrm{G}^{*}$ Power 3.1 program with a significance level of 0.05 , a statistical power of 0.95 , and a regression analysis effect size of 0.3 . The number of people calculated was 515 , and the total value was 508 .

\section{Variables}

The general characteristics included were age, grade, personality, peer relationship, academic satisfaction with dental hygiene, and average grade in the previous semesters. The variables for the determination of critical thinking were the tools developed by Yoon ${ }^{15)}$. A total of 27 items which consisted of systematicity (3 items), intellectual fairness (4 items), sound skepticism (4 items), objectivity (3 items), intellectual passion/curiosity (5 items), watchfulness (4 items), and confidence (4 items) was measured. The grading system attributed 5 points for a 'very well' response, and 1 point for a 'not at all' response. The Cronbach's $\alpha$ value of the research tool was 
0.812. The communication skill was determined using Lee's tool ${ }^{16)}$, which modified and supplemented the GICC (Global Interpersonal Communication Competence) developed by $\mathrm{Hur}^{17)}$. A total of 15 questions were asked about self-exposure, putting on the other's shoe, relieve of social tensions, assertiveness, concentration, interaction management, expressiveness, supportability, immediateity, efficiency, social adequacy, logic, goal perception, reaction, and noise control. The 5-point Likert-type scale was used, and the Cronbach's $\alpha$ value was 0.852 .

The problem-solving ability was measured using a scale developed by Lee et al. ${ }^{18)}$ with 30 items, including: clarification of the problem ( 6 items), seeking solutions (6 items), decision making (6 items), performing the solution (6 items), and evaluation and reflection (6 items). The 5-point Likert-type scale was used, and the Cronbach's $\alpha$ value was 0.936 .

\section{Analysis method}

Statistical analysis was conducted to examine the critical thinking, communication skills, and problem-solving ability of the subjects. T-test and ANOVA were performed to compare the critical thinking, communication skills, and problem-solving ability according to the general characteristics. Post-hoc analysis was performed to determine the significant difference between the groups. Levene statistics were used to determine the homogeneity of the variance test, and Scheffe analysis was also performed. The correlation between critical thinking, communication skill, and problem-solving ability was examined by Pearson's correlation analysis. Additionally, stepwise multiple regression analysis was performed to examine the factor effecting on the problem-solving ability. The data were analyzed using PASW statistics 18.0 (IBM Co., Armonk, NY, USA) and the significance level was 0.05 .

\section{Results}

\section{Critical thinking, communication skill, problem-solving} ability

Table 1 shows the critical thinking, communication skill, and problem-solving ability of dental hygiene students. In critical thinking, the intellectual fairness score was the highest (3.60), and it was followed by the variables of confidence, sound skepticism, and intellectual passion/ curiosity. However, systematicity was the lowest at 3.19. For communication skills, there was a higher reaction

Table 1. Critical Thinking, Communication Skill, and ProblemSolving Ability of Dental Hygiene Students

\begin{tabular}{lc}
\hline \multicolumn{1}{c}{ Variable } & Value \\
\hline Critical thinking & \\
Systematicity & $3.19 \pm 0.51$ \\
Intellectual fairness & $3.60 \pm 0.46$ \\
Sound skepticism & $3.35 \pm 0.59$ \\
Objectivity & $3.28 \pm 0.53$ \\
Intellectual passion/curiosity & $3.32 \pm 0.51$ \\
Watchfulness & $3.31 \pm 0.64$ \\
Confidence & $3.48 \pm 0.51$ \\
Total & $3.46 \pm 0.34$ \\
Communication skill & \\
Self-exposure & $3.51 \pm 0.84$ \\
Putting on the other's shoe & $3.93 \pm 0.74$ \\
Relieve social tensions & $3.16 \pm 0.89$ \\
Assertiveness & $3.55 \pm 0.82$ \\
Concentration & $4.18 \pm 0.76$ \\
Interaction management & $3.43 \pm 0.85$ \\
Expressiveness & $3.36 \pm 0.88$ \\
Supportability & $3.54 \pm 0.84$ \\
Immediateity & $3.61 \pm 0.75$ \\
Efficiency & $3.35 \pm 0.73$ \\
Social adequacy & $4.21 \pm 0.76$ \\
Logic & $3.11 \pm 0.82$ \\
Goal perception & $3.81 \pm 0.77$ \\
Reaction & $4.34 \pm 0.71$ \\
Noise control & $3.82 \pm 0.80$ \\
Total & $3.65 \pm 0.45$ \\
Clablem-solving ability & $3.74 \pm 0.54$ \\
Seeking solutions & $3.53 \pm 0.56$ \\
Decision making & $3.44 \pm 0.58$ \\
Performing the solution & $3.42 \pm 0.53$ \\
Evaluation and reflection & $3.37 \pm 0.60$ \\
Total & $3.50 \pm 0.47$ \\
\hline & \\
\hline &
\end{tabular}

Values are presented as mean \pm standard deviation. 
(4.34), social adequacy (4.21), and concentration (4.18) with an average value of 3.65 . The problem-solving ability was followed by clarification of the problem (3.74), seeking solutions (3.53), decision making (3.44), performing the solution (3.42), and evaluation and reflection (3.37).

2. Differences in critical thinking, communication skill, and problem-solving ability according to general characteristics

Critical thinking, communication skill, and problemsolving ability showed differences in personality, peer relationship, and academic satisfaction with dental hygiene according to the general characteristics. Furthermore, the more extroverted personalities displayed a higher critical thinking (3.53), communication skill (3.82), and problemsolving ability (3.58). Students who replied that their friendships were difficult obtained the highest scores for critical thinking ( $\mathrm{p}=0.016)$, but the lowest scores (3.11) for communication skills $(\mathrm{p}<0.001)$. Additionally, the problem-solving ability was highest among the students who reported a difficult peer relationship $(\mathrm{p}=0.001)$. The higher the academic satisfaction with dental hygiene, the higher the critical thinking (3.57), communication skill (3.81), and problem-solving ability (3.66) $(\mathrm{p}<0.001$; Table 2).

3. Relationship between critical thinking and communication skill with sub-domains of problemsolving ability

Critical thinking showed a high correlation in the following order: clarification of the problem (0.664), seeking solutions (0.606), performing the solution $(0.610)$, decision (0.601), and evaluation and reflection (0.570). The values for the communication skills were lower than

Table 2. Differences in Critical Thinking, Communication Skill, and Problem-Solving Ability according to General Characteristics

\begin{tabular}{|c|c|c|c|c|c|c|c|}
\hline \multirow{2}{*}{ Characteristic } & \multirow{2}{*}{$\mathrm{n}(\%)$} & \multicolumn{2}{|c|}{ Critical thinking } & \multicolumn{2}{|c|}{ Communication skill } & \multicolumn{2}{|c|}{ Problem-solving ability } \\
\hline & & Mean \pm SD & $\mathrm{p}$ & Mean \pm SD & $\mathrm{p}$ & Mean \pm SD & $\mathrm{p}$ \\
\hline \multicolumn{8}{|l|}{ Age (y) } \\
\hline 20 & $139(27.4)$ & $3.47 \pm 0.356$ & \multirow[t]{3}{*}{0.732} & $3.70 \pm 0.424^{\mathrm{b}}$ & \multirow[t]{3}{*}{0.018} & $3.54 \pm 0.514$ & \multirow[t]{3}{*}{0.411} \\
\hline 21 & $178(35.0)$ & $3.48 \pm 0.313$ & & $3.70 \pm 0.453^{\mathrm{a}}$ & & $3.50 \pm 0.425$ & \\
\hline 22 & $191(37.6)$ & $3.42 \pm 0.344$ & & $3.58 \pm 0.481^{\mathrm{a}}$ & & $3.47 \pm 0.483$ & \\
\hline \multicolumn{8}{|l|}{ Grade } \\
\hline $1 \mathrm{st}$ & $178(35.0)$ & $3.49 \pm 0.353$ & \multirow[t]{3}{*}{0.121} & $3.72 \pm 0.431^{\mathrm{b}}$ & \multirow[t]{3}{*}{0.004} & $3.56 \pm 0.500$ & \multirow[t]{3}{*}{0.069} \\
\hline 2nd & $186(36.6)$ & $3.47 \pm 0.334$ & & $3.67 \pm 0.470^{\mathrm{b}}$ & & $3.50 \pm 0.463$ & \\
\hline $3 \mathrm{rd}$ & $144(28.3)$ & $3.42 \pm 0.344$ & & $3.55 \pm 0.464^{\mathrm{a}}$ & & $3.43 \pm 0.443$ & \\
\hline \multicolumn{8}{|l|}{ Personality } \\
\hline Introverted & $274(53.9)$ & $3.41 \pm 0.327$ & \multirow[t]{2}{*}{$<0.001$} & $3.51 \pm 0.419$ & \multirow[t]{2}{*}{$<0.001$} & $3.43 \pm 0.478$ & \multirow[t]{2}{*}{0.001} \\
\hline Extroverted & $234(46.1)$ & $3.53 \pm 0.352$ & & $3.82 \pm 0.447$ & & $3.58 \pm 0.455$ & \\
\hline \multicolumn{8}{|l|}{ Peer relationship } \\
\hline Difficult & $9(1.8)$ & $3.51 \pm 0.434$ & \multirow[t]{3}{*}{0.016} & $3.11 \pm 0.397^{\mathrm{a}}$ & \multirow[t]{3}{*}{$<0.001$} & $3.58 \pm 0.658$ & \multirow[t]{3}{*}{0.001} \\
\hline Moderate & $232(45.7)$ & $3.42 \pm 0.335$ & & $3.49 \pm 0.418^{\mathrm{b}}$ & & $3.41 \pm 0.465$ & \\
\hline Good & $267(52.8)$ & $3.50 \pm 0.345$ & & $3.82 \pm 0.430^{\mathrm{c}}$ & & $3.57 \pm 0.461$ & \\
\hline \multicolumn{8}{|c|}{ Academic satisfaction with dental hygiene } \\
\hline Lower & $35(6.9)$ & $3.38 \pm 0.394^{\mathrm{a}}$ & \multirow[t]{3}{*}{$<0.001$} & $3.36 \pm 0.447^{\mathrm{a}}$ & \multirow[t]{3}{*}{$<0.001$} & $3.32 \pm 0.476^{\mathrm{a}}$ & \multirow[t]{3}{*}{$<0.001$} \\
\hline Middle & $291(57.3)$ & $3.41 \pm 0.308^{\mathrm{a}}$ & & $3.59 \pm 0.424^{\mathrm{b}}$ & & $3.42 \pm 0.410^{\mathrm{a}}$ & \\
\hline Higher & $182(35.8)$ & $3.57 \pm 0.365^{\mathrm{b}}$ & & $3.81 \pm 0.465^{\mathrm{c}}$ & & $3.66 \pm 0.521^{\mathrm{b}}$ & \\
\hline \multicolumn{8}{|c|}{ Average grade of the previous semester } \\
\hline$<2.0$ & $21(4.1)$ & $3.39 \pm 0.340$ & \multirow[t]{4}{*}{0.143} & $3.63 \pm 0.454$ & \multirow[t]{4}{*}{0.985} & $3.37 \pm 0.490$ & \multirow[t]{4}{*}{0.134} \\
\hline $2.0 \sim 3.0$ & $291(28.9)$ & $3.47 \pm 0.340$ & & $3.66 \pm 0.485$ & & $3.47 \pm 0.483$ & \\
\hline $3.0 \sim 4.0$ & $281(55.3)$ & $3.45 \pm 0.335$ & & $3.65 \pm 0.432$ & & $3.50 \pm 0.453$ & \\
\hline $4.0 \sim 4.5$ & $59(11.6)$ & $3.55 \pm 0.388$ & & $3.64 \pm 0.525$ & & $3.62 \pm 0.519$ & \\
\hline
\end{tabular}

Values are analysed by t-test and one-way ANOVA statistics.

SD: standard deviation.

${ }^{a, b, c}$ The same letter indicates no significant difference by Scheffe. 
Ji-Hyoung Han, et al. : Effects of Critical Thinking and Communication Skills on the Problem-Solving Ability

Table 3. Relationship between Critical Thinking and Communication Skill on Sub-Domains of Problem-Solving Ability

\begin{tabular}{lccccc}
\hline & $\begin{array}{c}\text { Clarification of } \\
\text { the problem }\end{array}$ & Seeking solutions & Decision making & $\begin{array}{c}\text { Performing } \\
\text { the solution }\end{array}$ & $\begin{array}{c}\text { Evaluation } \\
\text { and reflection }\end{array}$ \\
\hline Critical thinking & $0.664^{* *}$ & $0.606^{* *}$ & $0.601^{* *}$ & $0.610^{* *}$ & $0.570^{* *}$ \\
Communication skill & $0.496^{* *}$ & $0.472^{* *}$ & $0.452^{* *}$ & $0.490^{* *}$ & $0.467^{* *}$ \\
\hline
\end{tabular}

Values are analysed by Pearson correlation statistics.

$* * \mathrm{p}<0.01$.

Table 4. Factors Affecting the Problem-Solving Ability

\begin{tabular}{|c|c|c|c|c|c|}
\hline Variable & $\mathrm{B}$ & SE & $\beta$ & $\mathrm{t}$ & $\mathrm{p}$ \\
\hline Confidence $^{\mathrm{a}}$ & 0.254 & 0.033 & 0.276 & 7.728 & $<0.001$ \\
\hline Watchfulness $^{\mathrm{a}}$ & 0.159 & 0.026 & 0.215 & 6.165 & $<0.001$ \\
\hline Noise control $^{\mathrm{b}}$ & 0.100 & 0.018 & 0.171 & 5.500 & $<0.001$ \\
\hline Intellectual passion/curiosity ${ }^{\mathrm{a}}$ & 0.169 & 0.031 & 0.183 & 5.471 & 0.040 \\
\hline Sound skepticism ${ }^{\mathrm{a}}$ & 0.061 & 0.026 & 0.076 & 2.306 & 0.022 \\
\hline Putting on the other's shoe ${ }^{b}$ & 0.056 & 0.020 & 0.089 & 2.794 & 0.005 \\
\hline Objectivity $^{\mathrm{a}}$ & 0.069 & 0.025 & 0.078 & 2.788 & 0.006 \\
\hline Systematic $^{\mathrm{a}}$ & 0.075 & 0.031 & 0.082 & 2.447 & 0.015 \\
\hline Relieve social tensions ${ }^{\mathrm{b}}$ & -0.048 & 0.016 & -0.092 & -2.971 & 0.003 \\
\hline Efficiency $^{\mathrm{b}}$ & 0.059 & 0.020 & 0.092 & 2.911 & 0.004 \\
\hline \multicolumn{6}{|c|}{$\mathrm{F}=86.802, \mathrm{R}^{2}=0.636$, adjusted $\mathrm{R}^{2}=0.629, \mathrm{p}<0.001$} \\
\hline
\end{tabular}

Values are analysed by multiple regression statistics.

SE: standard error.

${ }^{\mathrm{a}}$ Critical thinking, ${ }^{\mathrm{b}}$ Communication skill.

that of critical thinking and it was associated with the variables in the following order: clarification of the problem (0.496), performing the solution (0.490), seeking solutions (0.472), evaluation and reflection (0.467), and decision making $(0.452)(\mathrm{p}<0.01$; Table 3$)$.

\section{Factors affecting the problem-solving ability}

Table 4 shows the results of the stepwise multiple regression analysis to examine the factors affecting the problem-solving ability of the sub-domains of general characteristics, critical thinking and communication skills. With critical thinking, the factors of confidence, watchfulness, intellectual passion/curiosity, sound skepticism, objectivity, and systematicity influenced the problem-solving ability. Whereas, with communication skills, noise control, thinking from the other side, relieve of social tensions, and efficiency affected the problem-solving ability. It also revealed a $63.6 \%$ explanatory power $(\mathrm{p}<0.05)$.

\section{Discussion}

This study aims to identify the effects of critical thinking and the communication skills of dental hygiene students on their problem-solving abilities. It also utilizes these subjects for the collection of basic data for the technology and ability improvement which would be required in the future.

In this study, the value for critical thinking was 3.46, communication skill was 3.65 , and the problem-solving ability was 3.50. However, in Kim and Yun's study ${ }^{19)}$ on nursing students, there was a slight difference between the results of this study in the areas of critical thinking, which was 3.49 , communication skills which was 3.64 , and problem-solving ability which was 3.33 . The problemsolving ability reported in these previous studies were somewhat lower than this study. In the study conducted by Yang $^{20)}$ among nursing students, the critical thinking value was 3.42, and the problem-solving ability was 3.84. The different results of the problem-solving abilities appear to 
be due to the differences in research tools, the academic year of the subjects, and the length of their education and curriculum. Yang's research ${ }^{20)}$ revealed that intellectual fairness was the highest in the sub-domain of critical thinking and that systematicity was the lowest at 3.17. The high intellectual fairness values among nursing and dental hygiene students are attributed to their scientific knowledge ${ }^{20)}$. The low level of systematicity reveals that learning is based on implicit memorization rather than critical thinking and self-directed learning. Systematization is an important aspect of problem-solving. It is the critical tendency to focus and explore carefully, without deviating from the core of the problem ${ }^{21)}$. Therefore, it is urgent to change the educational environment to one that strengthens systematicity.

The differences between critical thinking, communication skills, and the problem-solving ability according to personality, peer relationship, and academic satisfaction with dental hygiene were all statistically significant. Kim et al.'s research ${ }^{22)}$ on dental hygiene students, and the studies $^{20,21)}$ on nursing students revealed the differences in critical thinking and problem-solving ability according to personality and major satisfaction. The results of this study are similar to these previous studies. These results indicate that the dental hygienist and student's personality, friendship, and academic satisfaction with dental hygiene are factors related to critical thinking, communication skills, and problem-solving ability. The more outgoing the personality, the better the friendships. Moreover, the more satisfied they were with their career majors, the higher the relevance. In addition to these factors, a variety of professional educational changes and innovations are needed to improve critical thinking, communication, and problem-solving ability. This is both an anachronistic demand and a desirable result of increasing the practical value of education. The correlations between critical thinking and communication skills on the sub-domains of problem-solving abilities all revealed a positive correlation.

This is similar to the results of Kim and $\mathrm{Yun}^{19}$. However, in this study, we also revealed a correlation with the sub-domain of problem-solving ability, but in Kim and Yun's study ${ }^{19)}$, the problem-solving ability was grouped into one unit and correlations were observed. Students should be able to understand and analyze various situations given to them students in the field of dental hygiene in order to develop the critical thinking ability to judge efficiently. In addition, we should find ways to cultivate communication skills to maintain positive relationships with patients through the provision of quality health care services. Finally, we should strive to produce dental hygienists with the ability to perform evidence-based clinical work. This can be done by developing their problem-solving ability, and their ability to identify and mediate problems quickly and accurately ${ }^{23)}$.

The following factors influenced the ability to solve problems: confidence, prudence, intellectual enthusiasm/ interest, sound conference, objectivity and systematicity of critical thinking. This means that among the seven sub-regions of critical thinking, all but intellectual fairness affects the ability to solve problems. As mentioned above, students in the dental hygiene department have advanced scientific knowledge, so there is more injection-based memory-oriented education than critical thinking training ${ }^{23)}$. Thus, intellectual fairness can be interpreted as a natural consequence that does not affect the ability to solve a problem. Dental hygiene requires critical thinking because it requires analyzing the subject's information and applying the appropriate process to solve the problem. Communication skills are also required because they must identify problems and maintain interpersonal relationships through effective communication and interaction with patients. Effective problem-solving abilities are also required to cope with unpredictable situation. Based on these demands, it is deemed necessary to find ways to improve critical thinking, communication skills, and problem-solving abilities among dental hygiene students.

This study was conducted on some dental hygiene students, so we cannot generalize the results. It has the limitations of cross-sectional research on critical thinking and communication skills and problem-solving abilities. Subsequent studies suggest expanding the targets and regions, as well as a comparison and repetition of the study among the three-year and four-year systems. It is also thought that research will be needed to identify other variables besides critical thinking and communication skills that may affect the problem-solving abilities and to 
verify their effectiveness.

\section{Notes}

\section{Conflict of interest}

No potential conflict of interest relevant to this article was reported.

\section{Ethical approval}

This study was approved by the Institutional Ethics Board of Suwon Science College (IRB2-7008167-AB-N01-201805-HR-001-01).

\section{ORCID}

Ji-Hyoung Han, https://orcid.org/0000-0003-1613-2879

Eunsuk Ahn, https://orcid.org/0000-0002-9404-4826

Ji-Min Hwang, https://orcid.org/0000-0003-2199-8319

\section{References}

1. World Economic Forum: New vision for education: unlocking the potential of technology. World Economic Forum, Geneva, pp.4-6, 2015.

2. American Dental Education Association: ADEA competencies for the new general dentist. J Dent Educ 75: 932-935, 2011.

3. Kim MS, Park C, Kim YJ, Min CH, Oh HS: A study for developing critical thinking test (II): construction of the test. Korea Institute for Curriculum and Evaluation, Jincheon, 2002. $156 \mathrm{p}$.

4. Hwang JM, Han JH: Effects of critical thinking disposition and empathy on cultural competency in dental hygiene students. J Dent Hyg Sci 18: 24-31, 2018. https://doi.org/10.17135/jdhs.2018.18.1.24

5. Wilkins EM: Clinical practice of the dental hygienist. 10th ed. Lippincott Williams \& Wilkins, New York, pp.2-17, 2009.

6. Kim EK, Kim YJ, Kim CH, et al.: Education standardization and development direction of dental hygiene. Korean Dental Hygienists Association, Korean Association of Dental Hygiene Professors, Seoul, 2005. 246 p.

7. Jo HI, Lee MH: The mediating effect of prosocial behavior in the relation between empathic ability and psychological wellbeing. Korean Youth Res Assoc 17: 139-158, 2010.

8. Trenholm S, Jensen A: Interpersonal communication. 6th ed.
Oxford University Press, New York, 2008. 330 p.

9. Jeong GS, Kim, KA, Seong JA: The effect of learning style and critical thinking disposition on communication skill in nursing students. J Korean Acad Soc Nurs Educ 19: 413-422, 2013. https://doi.org/10.5977/jkasne.2013.19.3.413

10. Kim SJ, Kim HH: Impact of communication competence and empathy abilities on interpersonal relationship abilities among dental hygiene students. J Dent Hyg Sci 13: 304-313, 2013.

11. Choi E, Kim J: The relationship of core competencies (problem solving ability, communication ability, self-directed learning ability) to critical thinking. J Korean Acad Fundam Nurs 14: 412-419, 2007.

12. Kim EK, Kim YJ, Kim CH, et al.: Dental hygiene education standardization and development direction. Korean Dental Hygienists Association, Seoul, pp.74-85, 2004.

13. Heppner PP, Krauskopf CJ: An information-processing approach to personal problem solving. Couns Psychol 15: 371-447, 1987. https://doi.org/10.1177/0011000087153001

14. Park SH: The effects of the program for the improvement of college students' critical thinking ability. Korean J Educ Psychol 13: 93-112, 1999.

15. Yoon J: Development of an instrument for the measurement of critical thinking disposition: in nursing. Unpublished doctoral dissertation, Catholic University, Seoul, 2004.

16. Lee HS: Relationships among communication competence, communication types, organizational commitment of nurses. Unpublished master's thesis, Dankook University, Yongin, 2008.

17. Hur GH: Construction and validation of a global interpersonal communication competence scale. Korean $\mathbf{J}$ Journal Commun Stud 47: 380-408, 2003.

18. Lee WS, Park SH, Choi EY: Development of a Korean problem solving process inventory for adults. J Korean Acad Fundam Nurs 15: 548-557, 2008.

19. Kim DJ, Yun SH: Influence of communication competence and critical thinking disposition on problem-solving skills of nursing students. Korean J Health Commun 11: 167-177, 2016. https://doi.org/10.15715/kjhcom.2016.11.2.167

20. Yang HJ: Relationship between critical thinking disposition and problem solving ability of nursing students. J Korea Acad-Ind Cooper Soc 14: 6387-6394, 2013. https://doi.org/10.5762/KAIS.2013.14.12.6387

21. Kim YH, Kim YA: The influence of academic self-efficacy, 
and critical thinking disposition on problem solving ability of nursing students. J Korea Acad-Ind Cooper Soc 17: 589-598, 2016. https://doi.org/10.5762/KAIS.2016.17.9.589

22. Kim JH, Sung HK, Kim HJ: Critical thinking disposition and problem-solving ability of dental hygiene students. J Dent
Hyg Sci 14: 356-363, 2014.

23. Shim HS, Lee HN, Kim EM: A study on the critical thinking and problem-solving abilities of dental hygiene students. J Korean Soc Dent Hyg 17: 1171-1182, 2017.

https://doi.org/10.13065/jksdh.2017.17.06.1171 